\title{
CIDADES FRAGMENTADAS NA AMAZÔNIA: A SEGREGAÇÃO RESIDENCIAL ESPONTÂNEA EM BOA VISTA - RORAIMA - BRASIL
}

\author{
Jefferson Silva de Souza \\ Universidade Federal de Roraima - UFRR \\ Mestre em Geografia pelo Programa de Pós-Graduação em Geografia, PPG-GEO-UFRR \\ jeffersongeo1991@gmail.com
}

Artur Rosa Filho Prof. Dr. do Programa de Pós-Graduação em Geografia, PPG-GEO - UFRR artur.filho@ufrr.br

\section{RESUMO}

A segregação residencial espontânea reflete-se através de diversas ações promovidas por intermédio dos chamados "promotores imobiliários", aos quais são denominados de agentes produtores do espaço urbano. Assim, o recorte espacial deste estudo consiste em uma área que abrange parte dos bairros: Cauamé, Caçari, Cidade Satélite, além de parte das BR-401 e RR-205 em Boa Vista. Neste sentido, a pesquisa teve como objetivo compreender o processo de segregação residencial espontânea, a partir da implementação de condomínios horizontais fechados em Boa Vista-RR e entorno. Em relação à metodologia, os passos estabelecidos para que se atingisse o objetivo proposto foram: levantamento bibliográfico, pesquisa documental, além de visitas in loco. Concebeu-se que os condomínios horizontais fechados impulsionam mais ainda este modelo de segregação supracitado, já que o poder de aquisição das classes sociais mais abastadas Ihes permitem residir em modelos de moradia de alto padrão com os seus semelhantes sociais.

Palavras-Chave: Dinâmica imobiliária. Segregação residencial espontânea. Condomínios horizontais fechados. Boa Vista e entorno.

\section{FRAGMENTED CITIES IN THE AMAZON: SPONTANEOUS RESIDENTIAL SEGREGATION IN BOA VISTA - RORAIMA - BRAZIL}

\begin{abstract}
The spontaneous residential segregation is reflected through several actions promoted through the so-called "real estate developers", who are called agents producing urban space. Thus, the spatial outline of this study consists of an area that covers part of the neighborhoods: Cauamé, Caçari, Cidade Satélite, as well as part of BR-401 and RR-205 in Boa Vista. In this sense, the research aimed to understand the process of spontaneous residential segregation, from the implementation of horizontal condominiums closed in Boa Vista-RR and surroundings. Regarding the methodology, the steps established to reach the proposed objective were: bibliographic survey, documentary research, in addition to on-site visits. It was conceived that closed horizontal condominiums further drive this segregation model mentioned above, since the purchasing power of the wealthier social classes allows them to reside in high-standard housing models with their social counterparts.
\end{abstract}

Keywords: Real estate dynamics. Spontaneous residential segregation. Closed condominiums. Boa Vista and surroundings.

\section{INTRODUÇÃO}

O processo de segregação residencial espontânea tem como característica marcante o distanciamento das mais diferentes classes sociais, que em decorrência da disparidade existente

$\begin{array}{lllll}\text { Caminhos de Geografia } \quad \text { Uberlândia } & \text { v. 20, n. } 72 \quad \text { Dez/2019 } & \text { p. 217-229 Página } 217\end{array}$


entre as mesmas no que tange ao aspecto financeiro, não propicia as mesmas condições igualitárias de acesso aos mais variados modelos de habitação difundidos pelo setor imobiliário.

No Brasil, os exemplos mais marcantes deste processo se evidenciam essencialmente nas grandes metrópoles, onde há uma clara distinção do tipo de habitação que as mais diversas classes sociais têm acesso. No caso daquelas de menor poder aquisitivo, Ihes restam moradias em locais menos favorecidos, tais como: favelas, áreas em situação de vulnerabilidade, áreas de invasão, entre outras. Por outro lado, as classes mais abastadas dispõem de capital suficiente, de maneira que estes têm o poder de não apenas optarem pela localização de sua habitação, mas também dos mais variados modelos arquitetônicos.

Ainda em relação às classes altas, que se configuram como agentes ativos no processo de segregação residencial espontânea, Carlos (2004) afirma que este fato se refere a uma estratégia destas classes sociais que, em decorrência do elevado poder aquisitivo, inserem seus indivíduos diferencialmente na metrópole, sendo que seu uso está ligado à propriedade e, portanto, seu uso se submete à realização do valor, através de um ato de troca.

Sendo assim, a compreensão da chamada segregação residencial espontânea na cidade de Boa Vista, passa pela caracterização do processo de implementação de condomínios horizontais fechados na mesma, os quais são destinados diretamente para as classes alto poder aquisitivo. Destaca-se que a cidade até então não possuía empreendimentos imobiliários desta natureza, portanto, promovendo notáveis mudanças na dinâmica espacial da capital Roraimense.

Sobre esta questão, Paixão (2017) cita que com o crescimento urbano da cidade de Boa Vista, surgem em seu espaço novos serviços urbanos, entre eles a implementação de condomínios fechados e bairros residenciais em variadas regiões da capital. Outra questão notada também neste viés é a supervalorização nos últimos anos de várias localidades, principalmente em decorrência da chegada de shopping centers.

Assim, destaca-se que foi identificada, atualmente, a implementação de cinco condomínios horizontais fechados na cidade de Boa Vista e entorno, os quais compõem o presente estudo, que são: Condomínio Florais Boa Vista, Condomínio Garden Park Mall Residence, Residencial Ilhas Gregas, Condomínio Colina Park Chácara Club e, Condomínio Pátio Cauamé. Por fim, ressalta-se a importância de realizar a caracterização de cada um destes empreendimentos, fazendo ainda uma relação com o processo de segregação residencial espontânea, bem como o papel do setor imobiliário neste fenômeno.

\section{SEGREGAÇÃO RESIDENCIAL ESPONTÂNEA: BREVES CONSIDERAÇÕES}

O processo de segregação residencial constitui-se em uma prática bastante comum nas cidades brasileiras, principalmente nos grandes centros urbanos onde ocorre a concentração de um expressivo contingente populacional, desta forma, provocando a separação espacial de classes conforme seu poder aquisitivo.

Medeiros (2012) esclarece que a segregação residencial não é um fenômeno exclusivamente dos dias atuais, visto que, desde as cidades mais antigas, a sociedade já apresentava subdivisões no espaço em decorrência de suas diferenciações sociais, políticas e econômicas. Sendo assim, o que se vê hoje é um processo de segregação de forma mais acentuada.

Neste sentido, Sabatini (2003) define o processo de segregação como um fenômeno que está intrinsecamente ligado à realidade social, assim, configurando-se em uma relação espacial de separação ou proximidade territorial entre indivíduos de uma mesma classe social, podendo ainda se apresentar de várias formas, seja ela de cunho social, cultural, racial, religiosa e socioeconômica.

Nesta perspectiva, compreende-se que no processo de segregação residencial, pessoas de um mesmo poderio econômico tendem a ocupar os mesmos espaços destinados à moradia, provocando uma homogeneidade de classes que pode ser notada tanto nos condomínios fechados de alto padrão, bem como nos mais modestos bairros residenciais para as classes de baixo poder aquisitivo.

No Brasil, o processo de segregação residencial pode ser observado a partir do fenômeno da urbanização que teve início na primeira metade do século $X X$, consolidando-se em meados da década de 1970 quando a população urbana superou a população rural, fato este que se evidenciou principalmente nas grandes metrópoles brasileiras. Segundo Passos e Araújo (2014, p. 386):

$\begin{array}{lllll}\text { Caminhos de Geografia } & \text { Uberlândia } & \text { v. 20, n. } 72 & \text { Dez/2019 } & \text { p. 217-229 Página } 218\end{array}$




\begin{abstract}
O processo de urbanização transforma as cidades produzindo o fenômeno da centralização de poder em determinadas áreas: o espaço, diante das transformações no processo produtivo é cada vez mais dominado pelo valor de troca. Desse modo, os lugares são submetidos a um sistema de rentabilidade, se tornando então locais idealizados, criados por determinadas regras de mercado. Surgem assim áreas distintas no espaço urbano que irão se caracterizar pela forma de apropriação.
\end{abstract}

Como consequência, este processo acarretou em uma série de problemas de ordem urbana. Assim, na visão de Silva, Lopes e Monteiro (2015), o crescimento das cidades trouxe consigo problemas como, excesso de lixo, inundações, poluição do ar, ilhas de calor, carência de habitações, falta de segurança, dentre outros.

Neste viés, salienta-se que os referidos problemas de ordem urbana, foram fatores determinantes no processo de segregação residencial espontânea. No caso das classes sociais com renda mais elevada, estes passaram a optar por moradias, principalmente mais afastadas das áreas centrais das cidades, com o objetivo de obterem melhor qualidade de vida. Desta forma, Koch (2008) destaca que novos modelos de habitação modernos passaram a integrar a paisagem urbana das cidades, transformando-a e configurando-a, destacando-se principalmente condomínios fechados e bairros residenciais de alto padrão.

Frente a esta questão, os promotores imobiliários desempenham um importante papel, pois estes são responsáveis por ações determinantes que irão promover mudanças em determinada parcela do espaço, mudando não somente a paisagem, mas ganhando esta nova funcionalidade. Santos (1988) afirma que o setor imobiliário organiza o espaço de forma hierárquica, pois o mesmo é quem define ações como a comercialização e financiamento de terrenos.

Conforme Gomes et al. (2003), os promotores imobiliários colocam à venda loteamentos, os quais na maioria das vezes possuem pouca ou nenhuma infraestrutura, onde os compradores se organizam e lutam para obterem equipamentos urbanos e serviços coletivos, como por exemplo, asfalto, água encanada, energia elétrica, postos de saúde, escolas, dentre outros, gerando benefícios não somente para quem está produzindo seu espaço, mas também, para aqueles que deixaram suas terras "esquecidas" aguardando valorização.

Portanto, os promotores imobiliários reorganizam o espaço destinando loteamentos para a classe de alta renda, incorporando-os às melhores áreas da cidade, onde possui infraestrutura adequada, promovendo a construção de formas de moradia com arquitetura que atrai este público-alvo. Já para as classes sociais de menor poder econômico lhes restam sempre as áreas de menor valorização do espaço urbano, desprovidas de saneamento básico e em situação de vulnerabilidade. Enfim, são áreas pouco assistidas pelo poder público.

Por fim, a partir dessas considerações, a principal consequência do processo de segregação residencial é a fragmentação das cidades, desta maneira, opondo-se aos princípios das relações sociais que nela se processam, pois são as relações sociais entre os diferentes que tornam o espaço dinâmico. Assim, entende-se que o processo de segregação residencial espontânea é aquele onde o próprio indivíduo se autossegrega, resultante do preço da terra, e do quanto o mesmo pode pagar pela mesma. Já a segregação induzida se realiza em forma de imposição englobando sempre a população de baixa renda, já que esta não possui capital suficiente de forma que possam escolher onde podem residir.

\title{
A DINÂMICA DE (RE) PRODUÇÃO DO ESPAÇO URBANO EM BOA VISTA-RR: A AÇÃO DOS PROMOTORES IMOBILIÁRIOS E O PROCESSO DE SEGREGAÇÃO RESIDENCIAL ESPONTÂNEA
}

A cidade de Boa Vista (figura 1), capital do estado de Roraima, localizada na Região Norte do país, possui uma área territorial de $5.687 \mathrm{~km}^{2}$. Conforme dados estimados do IBGE (2017), sua população está estimada em 332.020 habitantes e apresenta uma densidade demográfica de 49,99 hab/km².

A capital limita-se com Pacaraima a Norte; Normandia a Nordeste; Bonfim a Leste; Cantá a Sudeste; Mucajaí a Sudoeste; Alto Alegre a Oeste e; Amajarí a Noroeste. Além de ser a capital estadual

$\begin{array}{lllll}\text { Caminhos de Geografia } & \text { Uberlândia } & \text { v. 20, n. } 72 & \text { Dez/2019 } & \text { p. 217-229 Página } 219\end{array}$


mais setentrional do Brasil é a única localizada totalmente acima da linha do Equador e a mais distante de Brasília, capital federal, e de São Paulo, principal metrópole do país (IBGE, 2017).

Figura 1 - Localização geográfica do município de Boa Vista, capital do estado de Roraima.

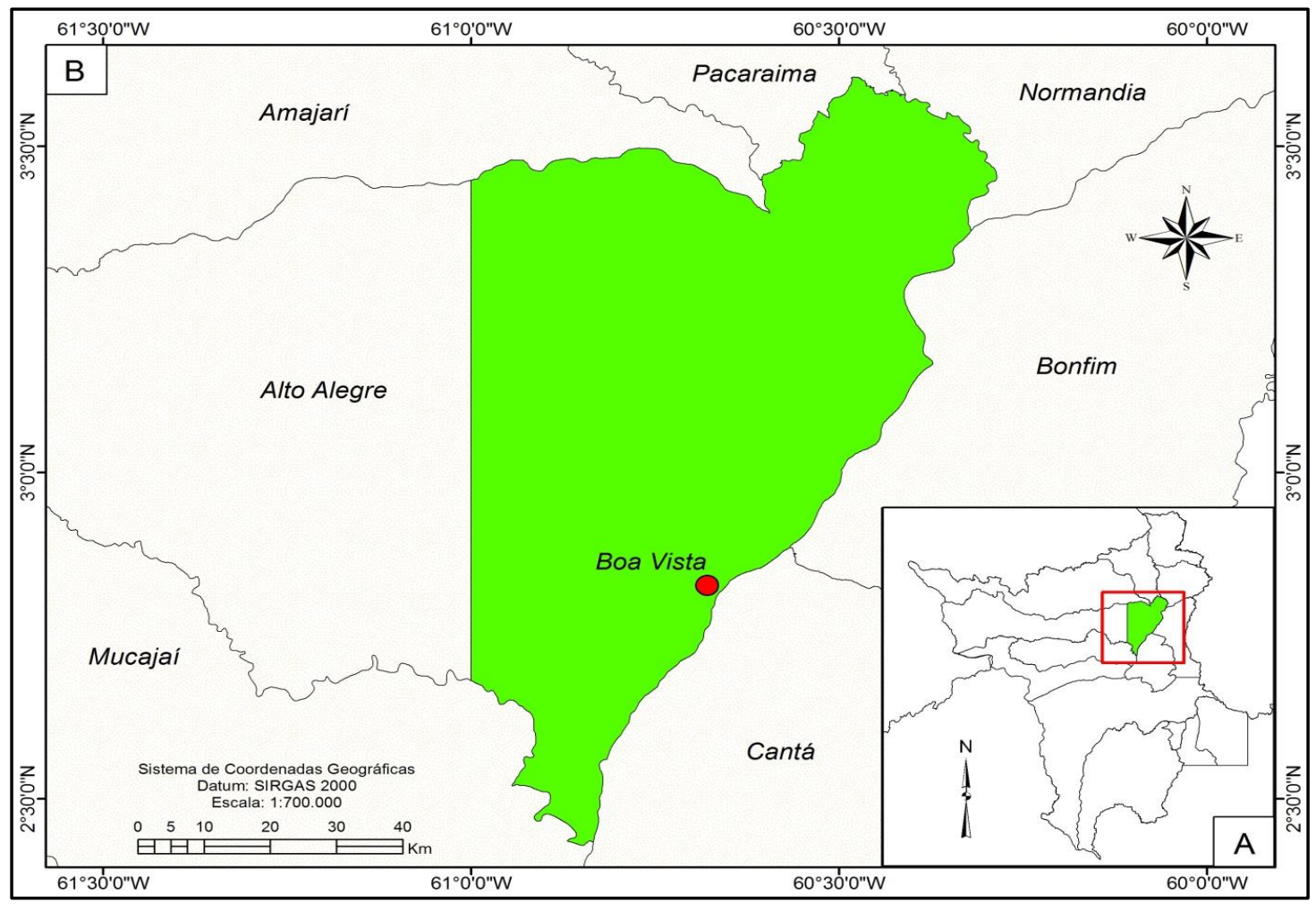

Fonte - IBGE (2011).

Neste sentido, a compreensão do processo de segregação residencial espontânea na cidade de Boa Vista passa pela análise do setor imobiliário, buscando compreender principalmente suas características, forma de atuação e público-alvo o qual são destinados os empreendimentos imobiliários de alto padrão, destacando principalmente, os condomínios horizontais fechados.

Ferreira e Silva (2007, p.10) citam que "a dinâmica imobiliária pode ser definida como uma somatória de processos que evidenciam a transformação e a valorização sobre o uso do solo em uma lógica de produção de imóveis ou de lotes ditos urbanizados". Neste mesmo ponto vista, cabe destacar que no processo de dinâmica imobiliária, amplas faixas de áreas metropolitanas ou até mesmo de cidades médias e pequenas são ocupadas por tipologias imobiliárias que além modificar a paisagem dos lugares, interferem diretamente no ritmo e modo de vida da sociedade.

Sendo assim, o espaço urbano das cidades é caracterizado por seus diferentes usos e sua produção é resultado da ação de agentes que promovem uma transformação deste espaço, desta forma, contribuindo para que haja especificidades nas mais diferentes parcelas de terra (LOPES JUNIOR e SANTOS, 2010). Portanto, dentre os agentes produtores do espaço urbano, destaca-se os promotores imobiliários, pois são eles que atuam diretamente no mercado imobiliário.

A expansão desses modelos de moradias modernos impulsionou o mercado imobiliário e a atuação dos promotores imobiliários tornou-se cada vez mais importante, pois na dinâmica imobiliária, são estes que fazem estudos detalhados de cada área de uma localidade, desta forma, interferindo diretamente nos elementos que diferenciam um condomínio horizontal fechado dos demais. Assim sendo, Botelho (2009, p. 114) cita que:

$\begin{array}{llllll}\text { Caminhos de Geografia } & \text { Uberlândia } & \text { v. 20, n. } 72 & \text { Dez/2019 } & \text { p. 217-229 Página } 220\end{array}$




\begin{abstract}
A oferta de novas áreas urbanas no mercado imobiliário é uma das opções que compõem a carteira de negócios dos agentes imobiliários, já que estes são considerados agentes transformadores do uso e ocupação do solo e das características dos estoques imobiliários, por isso terão todo interesse em criar, em localidades diferenciadas, novas concepções de apropriação espacial, no sentido de antecipar e assegurar frente aos demais empreendedores, a coordenação espacial na transformação da estrutura espacial urbana.
\end{abstract}

A implantação de habitações em novas áreas, criam novos focos de valorização do espaço urbano, pois estas passam a abrigar grandes empreendimentos imobiliários destinados em sua grande maioria às classes mais abastadas. Nesta perspectiva, a cidade de Boa Vista, apresenta-se como uma capital promissora para ação dos promotores imobiliários, em decorrência de seu processo de expansão urbana e crescimento demográfico a qual a mesma vem passando nas últimas décadas. Conforme Veras (2009, p. 210):

A cidade de Boa Vista, hoje, apresenta-se em acelerado crescimento urbano, englobando sempre novas áreas e extensões fragmentadas. Esse processo de reprodução do espaço urbano também nos coloca diante de novas formas que ganham novos conteúdos.

Neste sentido, os fatores citados impulsionaram cada vez mais o processo de segregação residencial espontânea em Boa Vista, principalmente em decorrência da implantação de condomínios horizontais fechados na cidade nos últimos quatro anos. Salienta-se que até mesmo áreas no entorno da cidade e pouco adensadas estão dando lugar a estes novos modelos de habitação moderna. A inserção de capital imobiliário tem atraído até mesmo empresas do ramo imobiliário de renome nacional. Assim sendo, Veras (2012) esclarece que a cidade Boa Vista vem passando por uma nova forma de interesses no mercado externo.

Consequentemente, as mudanças promovidas no espaço urbano de Boa Vista, principalmente por intermédio dos promotores imobiliários, repercutem fortemente no aumento do tamanho do espaço urbano da cidade nos últimos anos. Sendo assim, Cunha (2016) afirma que o crescimento do ponto de vista da questão imobiliária, tem ocorrido nas franjas da cidade.

Portanto, o processo de segregação residencial espontânea na cidade de Boa Vista, se intensificou nos últimos anos com a chegada de condomínios horizontais fechados na mesma. A implantação destes empreendimentos imobiliários dá ao espaço urbano de Boa Vista novas dinâmicas e funcionalidades, visto que estes promovem a expansão de infraestruturas em espaços antes rugosos.

\title{
O PROCESSO DE SEGREGAÇÃO ESPONTÂNEA NA CIDADE DE BOA VISTA A PARIR DA IMPLANTAÇÃO DE CONDOMÍNIOS HORIZONTAIS FECHADOS
}

Frente ao processo de (re) produção do espaço urbano na cidade de Boa Vista que se tem dado nos últimos anos no que se refere à dinâmica imobiliária, principalmente por intermédio da inserção de condomínios horizontais fechados na capital roraimense, observa-se que tal fenômeno intensificou e deu mais dinamismo ainda à chamada segregação residencial espontânea, que até então se materializava no espaço urbano roraimense por meio do lançamento de bairros residenciais voltados para as classes mais abastadas.

Logo, a atuação do mercado imobiliário na cidade de Boa Vista e entorno é dinâmico, fato este que pode ser percebido no dia a dia, essencialmente por conta da implementação de conjuntos habitacionais, dando ao espaço novas dinâmicas, formas e funcionalidades (VERAS, 2009). Portanto, os condomínios horizontais fechados também se inserem neste contexto, pois são empreendimentos imobiliários recentes na capital de Roraima. 
Sendo assim, Michelotto (2014) enfatiza que a produção do espaço e a expansão urbana é resultado da contínua necessidade da sociedade em busca de seus anseios e de suas distintas demandas, em que o processo de produção é acompanhado constantemente pela reorganização espacial. Nesta perspectiva, torna-se imprescindível caracterizar brevemente alguns dos principais condomínios horizontais fechados em processo de implementação na cidade de Boa Vista e também em seu entorno.

Nos últimos quatro anos, os promotores imobiliários têm investido maciçamente em ações de marketing, buscando vender uma imagem agradável e satisfatória de seus empreendimentos, cada um a seu modo, atuando principalmente em locais estratégicos de grande movimentação, como por exemplo, em shopping centers. Sendo assim, foram identificados a implementação de cinco condomínios horizontais fechados em Boa Vista e entorno, que são: (1) Condomínio Florais Boa Vista, (2) Condomínio Garden Park Mall Residence, (3) Residencial Ilhas Gregas, (4) Condomínio Colina Park Chácara Club e, (5) Condomínio Pátio Cauamé.

A seguir será possível identificar cada um deles no espaço geográfico roraimense, através do mapa de localização dos mesmos, para que a partir daí se faça a caracterização de cada um destes empreendimentos imobiliários integrantes da pesquisa (figura 2).

Figura 2 - Localização de futuros condomínios horizontais fechados em Boa Vista e entorno.

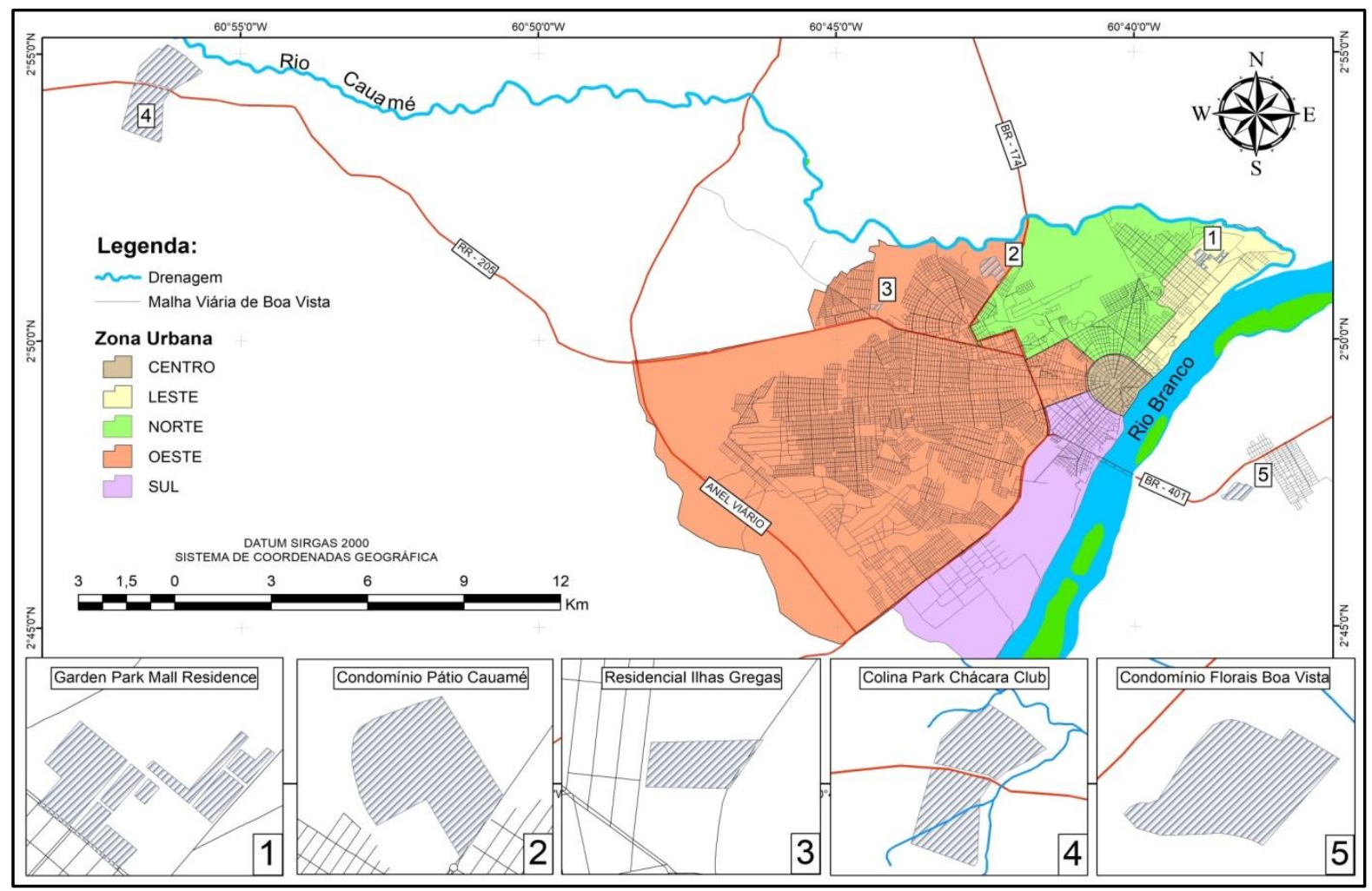

Frente à localização geográfica destes empreendimentos imobiliários em Boa Vista e entorno, será possível perceber que estes possuem características distintas, principalmente aqueles localizados nas bordas da cidade, pois são destinados principalmente para aqueles que buscam maior contato com o meio ambiente e longe da agitação urbana. A seguir será caracterizado cada um destes, iniciando-se num primeiro momento, pelo Condomínio Florais Boa Vista. 


\section{Condomínio Florais Boa Vista}

Sabe-se que a chegada de modelos de habitação de alto padrão em determinada localidade, intensifica 0 processo de segregação residencial espontânea. Assim, a implementação do condomínio Florais Boa Vista (figura 3) é uma realização da empresa mato-grossense Ginco Urbanismo, que em 2015 lançou seu produto imobiliário para a população boa-vistense de alto poder aquisitivo, após estudos técnicos realizados pela mesma, indicarem que a capital de Roraima apresenta um grande potencial para o mercado imobiliário.

O empreendimento em fase de edificação está localizado no entorno da cidade, às margens da BR401 a 6 minutos do centro da cidade. Sendo assim, Galvão (2007) enfatiza que ao longo dos últimos anos nas cidades brasileiras, os condomínios horizontais fechados têm se disseminado, principalmente ao longo de rodovias, o que possibilitou aos condôminos, praticamente uma quase que separação total da cidade tradicional.

Figura 3 - Futuras instalações do Condomínio Florais Boa Vista.

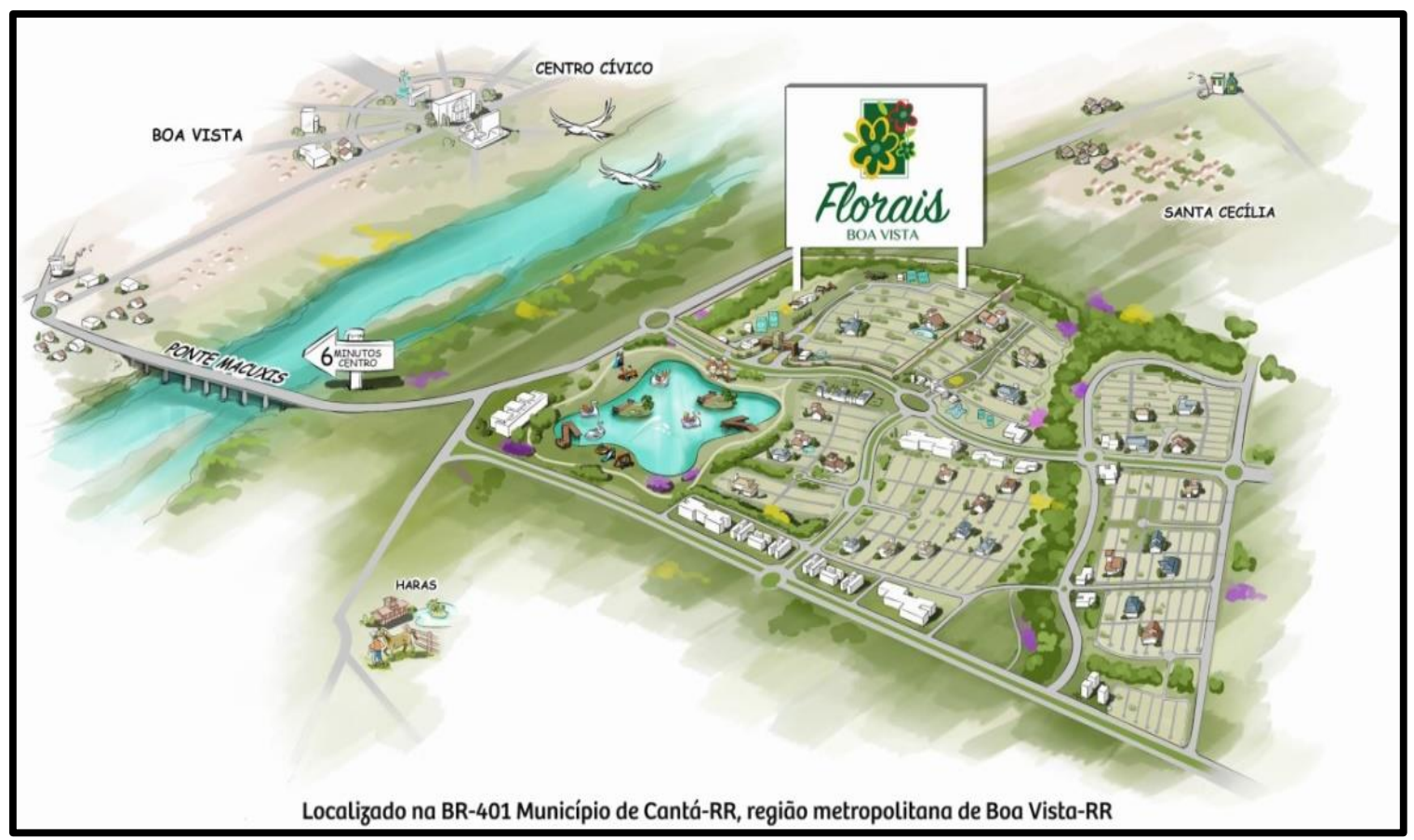

Fonte - Ginco-Urbanismo (2016).

Conforme dados obtidos junto ao site da empresa, o empreendimento contará com 471 lotes, dispostos em uma área total de $130.000 \mathrm{~m}^{2}$, que possuirão tamanhos de $448 \mathrm{~m}^{2}$ a $875 \mathrm{~m}^{2}$, e o condomínio possuirá um total de 21 quadras. O mesmo ainda terá todo o perímetro fechado por muros e portarias para controle de acesso, além da instalação de equipamentos de segurança e monitoramento. $\mathrm{Na}$ área interna do condomínio haverá rondas da equipe de segurança, com o objetivo de dar mais tranquilidade ainda aos condôminos (GINCO URBANISMO, 2017).

\section{Garden Park Mall Residence}

Diferentemente do condomínio Florais Boa Vista, o Garden Park Mall Residence que tem a empresa roraimense Ribeiro Campos Empreendimentos como idealizadora do projeto, busca oferecer à

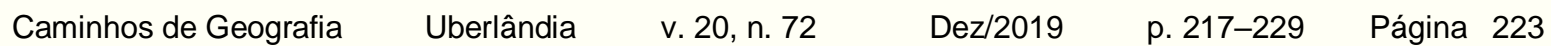


população consumidora deste tipo de habitação, uma aproximação com os principais equipamentos urbanos da cidade, dando ênfase maior ao shopping center que se encontra próximo ao mesmo (figura 4).

O projeto engloba também a construção de um hotel e prédios com salas comerciais, no Bairro Caçari, Zona Norte da capital. Na visão dos empreendedores dessa obra, Boa Vista é uma cidade em constante expansão e a região da Avenida Ville Roy é o foco de grande parte dos investimentos destinados ao desenvolvimento da cidade. Sendo este fator, determinante para que fosse definida a localização do condomínio (RIBEIRO CAMPOS EMPREENDIMENTOS).

Figura 4 - Futuras instalações do Garden Park Mall Residence.

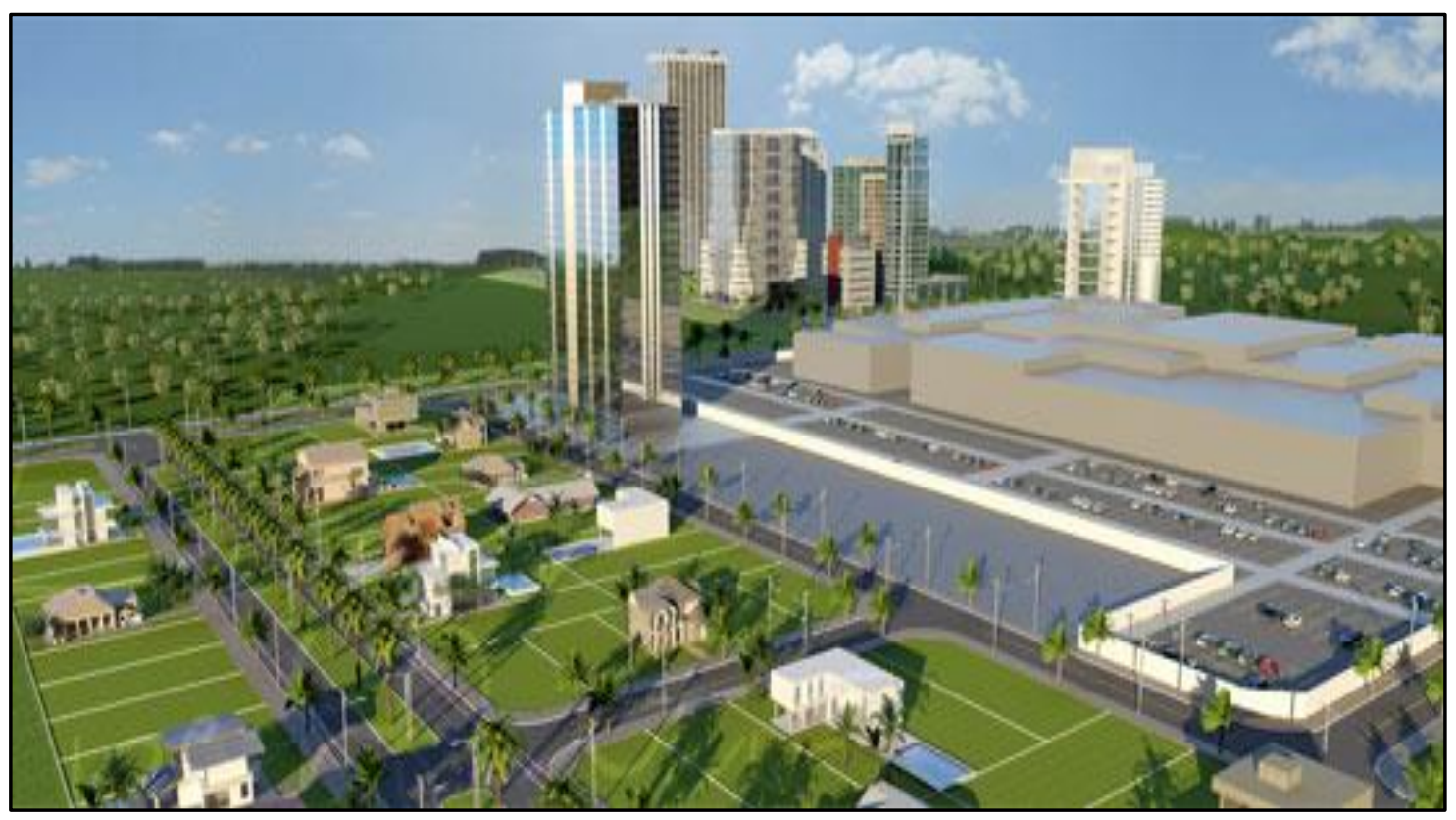

Fonte - Ribeiro Campos Empreendimentos (2016).

Ainda sobre os critérios de escolha para sua localização, a Ribeiro Campos empreendimentos (2017) esclareceu que a expansão desses novos empreendimentos em direção à Zona Leste da cidade apresenta características ideais para o consumo dessas inovações imobiliárias pela classe social que ali reside, adotando-se ainda uma forte conotação ao meio ambiente, visando promover uma relação harmoniosa entre o viver bem e a natureza.

Neste sentido, os agentes imobiliários adotam práticas cotidianas onde procuram fazer grande alusão ao verde em seus anúncios publicitários, destacando a natureza como capaz de suprir as necessidades dos consumidores. Reforçando esta ideia, Henrique (2005, p.1) esclarece que "a natureza, a infraestrutura e a qualidade de vida urbana são alguns dos aspectos vendidos pelo marketing imobiliário". Conforme dados obtidos junto a Ribeiro Campos empreendimentos (2017), a área total do empreendimento será de $465 \mathrm{mil} \mathrm{m}^{2}$, contabilizando um total de 212 lotes residenciais que variam de $450 \mathrm{~m}^{2}$ a $1000 \mathrm{~m}^{2}$.

\section{Colina Park Chácara Clube}

O Colina Park Chácara Clube é um empreendimento imobiliário lançado em 2015 sob a responsabilidade da empresa Terra Brasil. O projeto consiste em um condomínio horizontal fechado 
que esteja em harmonia com a natureza e longe da agitação da cidade, localizado às margens da RR-205 que liga a cidade de Boa Vista ao município de Alto Alegre (figura 5). O projeto contemplou na primeira fase, o lançamento de 746 lotes que variam entre 5 mil a 50 mil metros quadrados (JORNAL RORAIMA EM FOCO, 2015).

O valor simbólico atribuído à natureza se constitui como um elemento primordial nas ações de marketing das empresas que pretendem edificar esses empreendimentos num futuro próximo. A localização dos mesmos em áreas pouco adensadas, como é caso da maioria dos futuros condomínios em Boa Vista e entorno, tornam os preços dos lotes mais valorizados, sendo esta uma realidade cada vez mais presente nas cidades brasileiras.

Figura 5 - Divulgação do Colina Park Chácara Club.

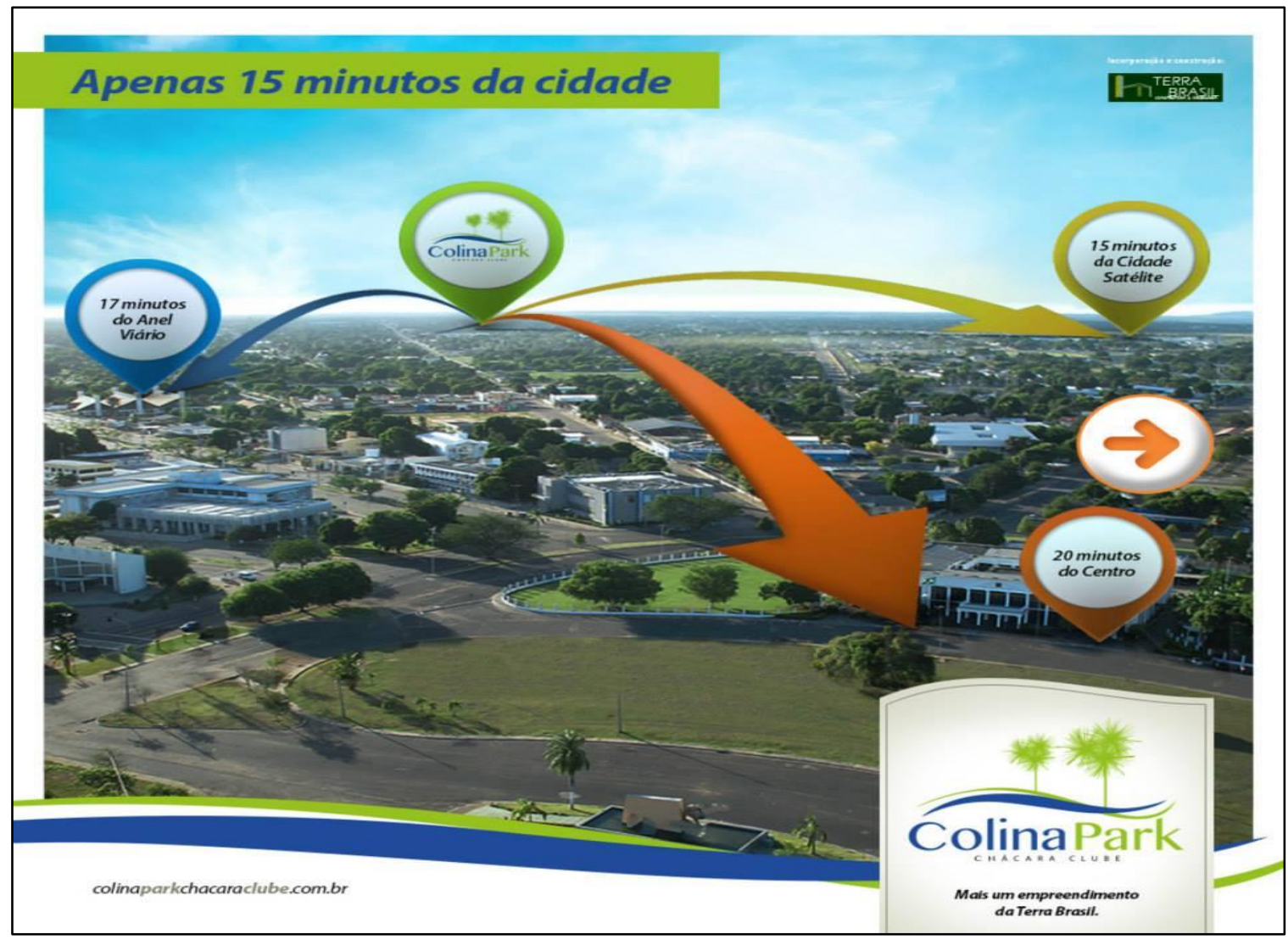

Fonte - Terra Brasil (2016).

Nesta perspectiva, Souza e Silva Junior (2017) afirmam que os condomínios horizontais fechados configuram-se como um novo modo de viver no espaço urbano, onde o marketing atribui forte conotação a uma vida em perfeita sintonia com o meio ambiente, longe dos problemas urbanos.

\section{Residencial Ilhas Gregas}

O condomínio horizontal fechado llhas Gregas é mais um empreendimento do ramo imobiliário lançado em Boa Vista pela empresa Terra Brasil no final do segundo semestre de 2016. A empresa aponta que a principal justificativa para o lançamento da obra é a localização estratégica do mesmo na Av. Universo, lote 500, quadra 709, bairro Cidade Satélite (Zona Oeste), que além da infraestrutura completa, como água encanada, rede de esgoto, energia, ruas asfaltadas, iluminação pública, o bairro também já oferece posto de saúde, escola, creche e posto de combustível (figura 6).

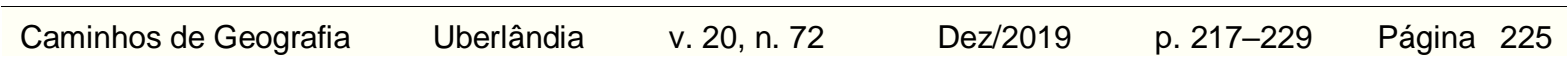


Figura 6 - Localização do Futuro empreendimento no bairro Cidade Satélite.

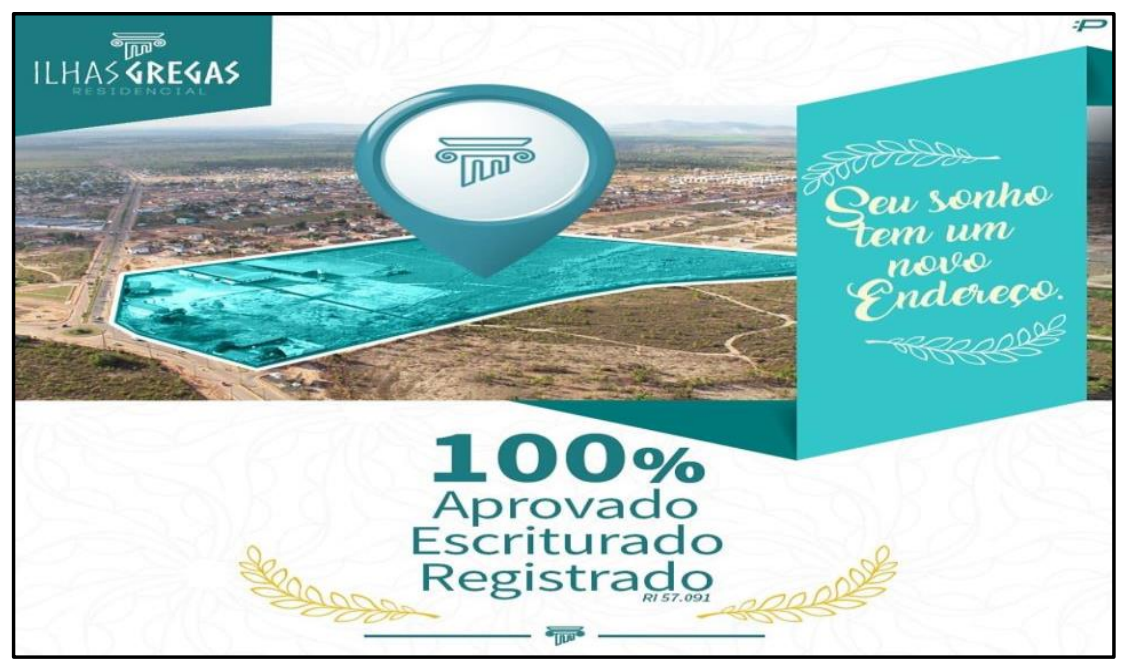

Fonte - Terra Brasil (2017).

O projeto contempla 269 lotes distribuídos numa área total de 46 mil metros quadrados, que contará com portaria para o controle do acesso de pessoas e veículos, além dos sistemas de vigilância e monitoramento que auxiliarão na segurança do mesmo. Haverá ainda vigilância interna por parte da equipe de segurança (TERRA BRASIL, 2017).

O Residencial Ilhas Gregas contemplará também espaços de lazer composto por quadra poliesportiva, playground, piscinas para adultos e crianças, churrasqueira e salão de festas, que assim como os demais empreendimentos até aqui descritos, o uso destes espaços será exclusivo para os futuros condôminos (TERRA BRASIL, 2017).

\section{Condomínio Pátio Cauamé}

O último grande empreendimento em processo de implementação na cidade de Boa Vista, está localizado no bairro Cauamé, zona Oeste da capital, próximo ao Pátio Roraima Shopping. Este recebe o nome de condomínio Pátio Cauamé, fazendo parte ainda de um grande projeto do grupo Saphyr, em parceria com a empresa Roraimense Vinhal empreendimentos que visa promover a valorização do shopping center, do hotel e do supermercado que também estão localizados na região (figura 7).

Figura 7 - Visão panorâmica de todo o complexo próximo ao condomínio Pátio Cauamé.

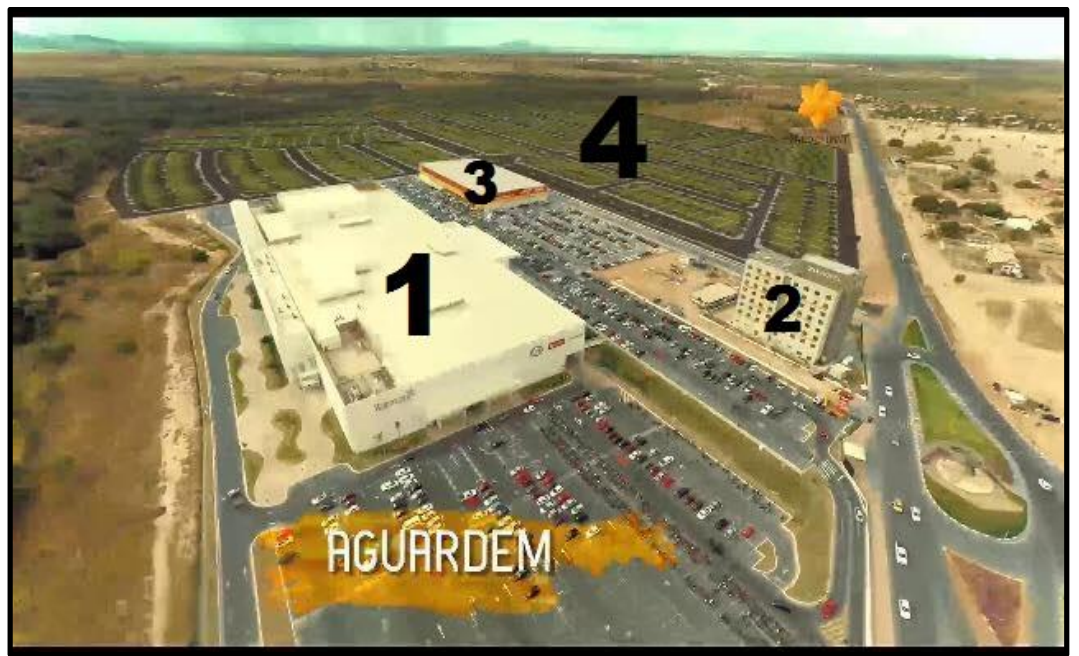

Fonte - Vinhal empreendimentos (2017). Legenda: 1 - Pátio Roraima Shopping; 2 - Zii Hotel; 3 Supermercado Nova Era; 4 - Futuras instalações do Condomínio Pátio Cauamé.

Caminhos de Geografia Uberlândia $\quad$ v. 20, n. $72 \quad$ Dez/2019 $\quad$ p. 217-229 Página 226


De acordo com o administrador do Pátio Roraima Shopping, a ideia é promover a criação de um complexo multiuso, visto que o futuro empreendimento irá contribuir com o desenvolvimento da região, agregando valores sociais, econômicos e ecológicos (JORNAL FOLHA DE BOA VISTA, 2015).

Diante do exposto, considera-se que a partir dessa nova realidade, a expansão desses novos produtos na cidade de Boa Vista e entorno, promove uma nova realidade socioespacial, na qual os espaços tornam-se cada vez mais dinâmicos, visto que, ganham o que Spósito (2003) chama de novos conteúdos sociais e econômicos.

A área compreenderá um total de 611 lotes que variam de $337 \mathrm{~m}^{2}$ a $602 \mathrm{~m}^{2}$ em uma área total de 449.142,09 $\mathrm{m}^{2}$. O empreendimento é fruto da parceria do Grupo Saphyr com empresas locais do ramo imobiliário, como é o caso da Vinhal Empreendimentos, que atua diretamente na divulgação e comercialização dos lotes (JORNAL FOLHA DE BOA VISTA, 2015).

Por fim, no que se refere à infraestrutura do futuro condomínio, os empreendedores esclareceram que a mesma está sendo realizada totalmente pela iniciativa privada, contemplando esgotamento sanitário, drenagem, água encanada, energia, pavimentação asfáltica, calçadas.

\section{CONSIDERAÇÕES FINAIS}

A segregação residencial espontânea atualmente é um fenômeno presente não somente nas grandes metrópoles, de forma que extrapolou barreiras e se faz presente até mesmo em médias cidades, como é o caso da capital do estado de Roraima, Boa Vista, que nos últimos anos tem evidenciado este processo com a chegada de condomínios horizontais fechados de alto padrão.

Sendo assim, após a constatação da chegada desses novos empreendimentos imobiliários em Boa Vista, verificou-se que o processo de segregação residencial espontânea foi impulsionado, visto que, outrora este processo se dava somente através da expansão de bairros residenciais nas áreas mais nobres da cidade.

Notou-se ainda que a implementação dos respectivos condomínios horizontais fechados ocorre em regiões da cidade que não foram escolhidas de forma aleatória, pois cada um destes tem sua finalidade. Este fato ocorre, essencialmente porque no processo de segregação residencial espontânea é a classe dominante quem dita essa lógica em decorrência do seu poder de aquisição.

Entende-se ainda que a chegada de condomínios horizontais fechados na cidade de Boa Vista eleva o grau de fragmentação da mesma e ainda impulsiona os contrastes sociais já existentes, interferindo diretamente na forma de reprodução das relações sociais, não permitindo o contato direto com classes sociais de menor poder econômico.

Por fim, destaca-se que a implementação de novos empreendimentos imobiliários provoca mudanças no padrão de ocupação dessas novas áreas, pois, além de induzir demandas a consumirem novos modelos habitacionais, provoca ainda o aumento da densidade populacional de suas respectivas localidades, visto que, morar entre seus semelhantes sociais é um dos principais aspectos das ações de marketing que motivam diversas famílias na escolha residencial.

\section{REFERÊNCIAS}

BOTELHO, D. N. Os agentes imobiliários e as transformações intra-urbanas: o caso dos condomínios horizontais fechados em Uberlândia - MG. Revista [online] Caminhos de Geografia, Uberlândia, v. 10, n. 32, p. 126-138, dez. 2009. Disponível em:

<http://www.seer.ufu.br/index.php/caminhosdegeografia/article/view/15892/8970> Acesso em: 12 ago. de 2017.

CARLOS, A. F. O espaço urbano: novos escritos sobre a cidade. São Paulo: Contexto, 2004.

CUNHA, V. P. A (re) produção como forma de valorização do espaço urbano em Boa Vista-RR: um estudo no bairro Aeroporto e entorno no período de 2000 a 2015. 2016. 158f. Dissertação (Mestrado em Geografia) - Instituto de Geociências, Universidade Federal de Roraima, Boa Vista, 2016.

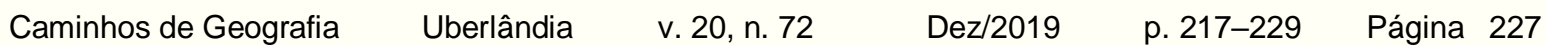


FERREIRA, A. L. A.; SILVA, A. F. C. Novas Dinâmicas Imobiliárias e Redefinição da Estrutura Territorial: o caso da área metropolitana de Natal/RN. Encontro Nacional da ANPUR, 12., 2007, Belém. Anais... Belém: ANPUR, 2007.

GALVÃO, A. A. Condomínios horizontais fechados: Segregadores ou segregados? - Um estudo de caso no município de Maringá/Paraná. 2007. 140f. Dissertação (Mestrado em Geografia) - Centro de Ciências Humanas Letras e Artes, Universidade Estadual de Maringá, Maringá, 2007.

GINCO URBANISMO. Florais Boa Vista: um novo estilo de vida. Disponível em: <http://ginco.com.br/empreendimentos/11/florais-boa-vista> Acesso em: 16 jun. de 2017.

GOMES, R. C. C.; SILVA, A. B.; SILVA, V. P. Política habitacional e urbanização no Brasil. Revista electrónica de geografía y ciencias sociales, Barcelona, v. 7, n. 146, ago. 2003. Disponível em: <http://www.ub.edu/geocrit/sn/sn-146(083).htm> Acesso em: 04 jun. 2017.

HENRIQUE, W. A felicidade não tem preço tem endereço: Condomínios, Loteamentos e Apropriação da Natureza. Revista Electrónica de Geografía y Ciências Sociales, Barcelona, v. 9, n. 194, p. 1-10, ago. 2005.

IBGE. Instituto Brasileiro de Geografia e Estatística. Roraima: Boa Vista - Estimativa da População. Disponível em: <https://cidades.ibge.gov.br/xtras/temas.php?codmun=140010\&idtema=130> Acesso em: 18 abr. 2017.

JORNAL FOLHA DE BOA VISTA. Pátio Roraima Comemora Amanhã primeiro ano de funcionamento. 2015. Disponível em: <http://folhabv.com.br/noticia/Patio-Roraima-comemoraamanha-primeiro-ano-de-funcionamento/11804> Acesso em: 30 abr. de 2017.

JORNAL RORAIMA EM FOCO. Boa Vista vai ganhar primeiro loteamento de chácaras clube. 2015. Disponível em: <http://www.roraimaemfoco.com/boa-vista-vai-ganhar-primeiro-loteamento-dechacaras-clube> Acesso em: 30 abr. de 2017.

$\mathrm{KOCH}, \mathrm{M}$. R. Condomínios fechados: as novas configurações do urbano e a dinâmica imobiliária. Revista Eletrônica FEE, Porto Alegre, v. 35, n. 3, p. 99-116, fev. 2008.

LOPES JUNIOR, W. M.; SANTOS, R.C.B. Reprodução do espaço urbano e a discussão de novas centralidades. Revista RA'E GA, Curitiba, n. 19, p. 107-123. 2010. https://doi.org/10.5380/raega.v19i0.14827

MEDEIROS, A. K. S. Exclusão social e projetos habitacionais: um estudo sobre conjuntos habitacionais, segregação e exclusão social em Natal/RN. 2012. 159f. Dissertação (Mestrado em Arquitetura e Urbanismo) - Universidade Federal do Rio Grande do Norte, Natal, 2012.

MICHELOTTO, L. D. G. Expansão Urbana e Sustentabilidade: análise do setor Leste de Uberlândia, MG. 2014. 164f. Dissertação (Mestrado em Geografia) - Instituto de Geografia, Universidade Federal de Uberlândia, Uberlândia, 2014.

PAIXÃO, F. R. S. Globalização e novas territorialidades em Roraima: o caso do setor imobiliário em Boa Vista. 3., 2017, Boa Vista. Anais... Boa Vista: EDUFRR, 2017.

PASSOS, A. N. e ARAÚJO, W. M. Desigualdade, exclusão e segregação espacial em Belo Horizonte: antigos personagens e novas distinções no bairro de Lourdes. Simpósio de Ciências Sociais: Cidade e Democracia, 3., 2014, Belo Horizonte. Anais... Belo Horizonte: PUC MINAS, 2014.

RIBEIRO CAMPOS EMPREENDIMENTOS. Garden Park Mall Residence. Disponível em: <http://gardenparkmallresidence.com.br/rcempreendimentos.html> Acesso em 30 nov. de 2017.

SABATINI, F. La segregación residencial em las ciudades latino americanas: causas, posibles políticas y rol de os mercados. In: ARENAS, F.; HIDALGO, R; COLL, J. L.(Org.). Los nuevos modos de gestión de la metropolización. Santiago, Chile: Pontífica Universidad Católica de Chile, 2003.

SANTOS, M. Metamorfose do espaço habitado. São Paulo: Hucitec, 1988.

SILVA, G.C.; LOPES, W.G.R.; MONTEIRO, M.S.L. A Presença de condomínios horizontais e loteamentos fechados nas cidades contemporâneas: expansão e transformações do espaço urbano de Teresina, Piauí. Revista GEOSUL, Florianópolis, v. 30, n. 59, p 167-187, jan./jun. 2015. https://doi.org/10.5007/2177-5230.2015v30n59p145 
SOUZA, M. O.; SILVA JUNIOR, O. F. Os condomínios fechados e a produção do espaço urbano em Mossoró: Segregação e acumulação do capital imobiliário. Revista Pensar Geografia, Mossoró, v.1, n.1, p. 7-27, jun. 2017. Disponível em:

<http://periodicos.uern.br/index.php/PENSARGEO/article/view/2435/1321> Acesso em: 31 jul. de 2017. https://doi.org/10.26704/rpgeo.v1n1p7

SPÓSITO, M. E. B. A cidade dentro da cidade: uma Edge City em São José do Rio Preto. Revista electrónica de geografía y ciencias sociales, Barcelona, v. 7, n. 146, ago. 2003. Disponível em: <http://www.ub.edu/geocrit/sn/sn-146(045).htm> Acesso em: 15 nov. de 2017.

TERRA BRASIL. Residencial Ilhas Gregas. 2017. Disponível em: <http://ilhasgregasresidencial.com.br/> Acesso em: 20 jul. de 2017.

VERAS, A. T. R. A produção do espaço urbano em Boa Vista - Roraima. 2009. 235f. Tese (Doutorado em Geografia Humana) - Faculdade de Filosofia, Letras e Ciências humanas, Universidade de São Paulo, São Paulo, 2009.

Rugosidades e tendências atuais na dinâmica da produção do espaço urbano em Boa Vista - Roraima In: MAGALHÃES, M. G.; SOUZA, C. M. (orgs) RORAIMA/BOA VISTA: Temas sobre o regional e local. Boa Vista: Editora da UFRR, 2012. p. 122-148.

Recebido em: 24/06/2018

Aceito para publicação em: 26/11/2019 